\title{
Description of three female 24-h ultra-endurance race winners in various weather conditions and disciplines
}

Chlíbková, Daniela ; Rosemann, Thomas ; Knechtle, Beat ; Nikolaidis, Pantelis Theodoros ; Žákovská, Alena ; Sudi, Karl

\begin{abstract}
A The incidence of exercise-associated hyponatremia (EAH) is higher in women than in men. We present three cases of a very mild post-race EAH in female winners of three 24-h ultra races in various weather conditions and disciplines with post-race plasma sodium $\left[\mathrm{Na}^{+}\right]$levels of $134 \mathrm{mM}$ (Case 1), $133 \mathrm{mM}$ (Case 2) and $134 \mathrm{mM}$ (Case 3). Moreover, Case 1 and Case 2 showed elevated creatine kinase concentrations of $>10,000$ $\mathrm{U} / \mathrm{l}$ with an absence of renal function abnormality. The common characteristics were female sex, veteran recreational category, long race experience in the particular sports discipline, excellent race performance, similar total weekly training hours and the presence of luteal phase of the menstrual cycle during the race. Hematocrit and hemoglobin decreased and post-race $\mathrm{K}^{+} / \mathrm{Na}^{+}$ratio in urine increased in all three cases. In addition, an increased body mass and a decreased urine specific gravity and urine osmolality suggested over-drinking in Case 1 . A decrease in the glomerular filtration rate and creatine clearance accompanied by an increase in urine $\left[\mathrm{Na}^{+}\right]$may contribute to fluid overload in Cases 2 and 3. Furthermore, urine osmolality reached a level indicating antidiuretic hormone secretion in all the present cases. Therefore, we recommend that race medical personnel should not forget to look for EAH even in fast and experienced female athletes and during races in different environmental conditions.
\end{abstract}

DOI: https://doi.org/10.4077/CJP.2017.BAF443

Posted at the Zurich Open Repository and Archive, University of Zurich ZORA URL: https://doi.org/10.5167/uzh-139283

Journal Article

Originally published at:

Chlíbková, Daniela; Rosemann, Thomas; Knechtle, Beat; Nikolaidis, Pantelis Theodoros; Žákovská, Alena; Sudi, Karl (2017). Description of three female 24-h ultra-endurance race winners in various weather conditions and disciplines. Chinese Journal of Physiology, 60(4):231-241.

DOI: https://doi.org/10.4077/CJP.2017.BAF443 


\title{
Description of Three Female 24-h Ultra-Endurance Race Winners in Various Weather Conditions and Disciplines
}

\author{
Daniela Chlíbková ${ }^{1}$, Thomas Rosemann ${ }^{2}$, Beat Knechtle ${ }^{2}$, Pantelis T. Nikolaidis ${ }^{3}$, \\ Alena Žákovská ${ }^{4}$, and Karl Sudi ${ }^{5}$ \\ ${ }^{1}$ Centre of Sports Activities, Brno University of Technology, Brno, 64300, Czech Republic \\ ${ }^{2}$ Institute of Primary Care, University of Zurich, Zurich, 8091, Switzerland \\ ${ }^{3}$ Exercise Physiology Laboratory, Nikaia, 18450, Greece \\ ${ }^{4}$ Institute of Experimental Biology, Masaryk University, Brno, 61137, Czech Republic \\ and \\ ${ }^{5}$ The Private University of the Principality of Liechenstein, 9495, Liechenstein
}

\begin{abstract}
A The incidence of exercise-associated hyponatremia (EAH) is higher in women than in men. We present three cases of a very mild post-race EAH in female winners of three 24-h ultra races in various weather conditions and disciplines with post-race plasma sodium $\left[\mathrm{Na}^{+}\right]$levels of $134 \mathrm{mM}$ (Case 1), $133 \mathrm{mM}$ (Case 2) and $134 \mathrm{mM}$ (Case 3). Moreover, Case 1 and Case 2 showed elevated creatine kinase concentrations of $>\mathbf{1 0 , 0 0 0} \mathrm{U} / \mathrm{l}$ with an absence of renal function abnormality. The common characteristics were female sex, veteran recreational category, long race experience in the particular sports discipline, excellent race performance, similar total weekly training hours and the presence of luteal phase of the menstrual cycle during the race. Hematocrit and hemoglobin decreased and post-race $\mathrm{K}^{+} / \mathrm{Na}^{+}$ratio in urine increased in all three cases. In addition, an increased body mass and a decreased urine specific gravity and urine osmolality suggested over-drinking in Case 1. A decrease in the glomerular filtration rate and creatine clearance accompanied by an increase in urine $\left[\mathrm{Na}^{+}\right]$may contribute to fluid overload in Cases 2 and 3. Furthermore, urine osmolality reached a level indicating antidiuretic hormone secretion in all the present cases. Therefore, we recommend that race medical personnel should not forget to look for EAH even in fast and experienced female athletes and during races in different environmental conditions.
\end{abstract}

Key Words: mountain biking, running, 24-h-race

\section{Introduction}

Exercise-associated hyponatremia (EAH) can occurr during or up to $24 \mathrm{~h}$ after physical activity (60). Even though most cases of EAH have minimal or absent complications and do not require medical treatment, some cases require rapid diagnosis and therapy to prevent deterioration into complications and death $(8,60)$. EAH may occur in those athletes who overdrink persistently during prolonged exercise, who also have an inappropriate release of antidiuretic hormone $(\mathrm{ADH})$ in response to exercise or some related condition that prevents normal urine output, and/or their bodies cannot mobilise osmotically inactive sodium stores adequately $(30,52$, 53). Other minor factors include sweat sodium losses, atrial natriuretic peptide (ANP), brain natriuretic peptide elevations and a rapid absorption of

Corresponding author: Prof. Dr. med. Beat Knechtle, Facharzt FMH für Allgemeinmedizin, Gesundheitszentrum St. Gallen, Vadianstrasse 26, 9001 St. Gallen, Switzerland, Tele: +41 (0) 7122693 00, Tele: +41 (0) 7122693 01, E-mail: beat.knechtle@hispeed.ch

Received: May 12, 2016; Revised (Final Version): December 29, 2016; Accepted: February 16, 2017.

(C2017 by The Chinese Physiological Society and Airiti Press Inc. ISSN : 0304-4920. http://www.cps.org.tw 
water from the gastrointestinal tract (8).

Multiple risk factors, such as extreme hot or cold environmental conditions, have also been associated with EAH (31). Heat stress and temperatures higher than $28^{\circ} \mathrm{C}$ seemed to increase the incidence of EAH and heat stroke during a marathon $(3,59)$. $\mathrm{EAH}$ has also been observed in ultra-endurance races held in extreme cold due to an excessive fluid consumption and/or inadequate sodium intake (64). Until recently, the possibility of simultaneously developing EAH and rhabdomyolysis would be considered rare; however, cases have been reported around the world $(29,35)$.

Female sex is considered a risk factor for developing EAH (60), since the incidence of EAH is greater in women than in men $(1,10,26,27,47)$. Therefore, in the present study, we focused on three female winners of 24-h ultra-endurance races; all of them developed mild EAH under various weather conditions and in different ultra-endurance sports disciplines.

\section{Materials and Methods}

\section{Ethical Approval}

Research within the project proceeded in accordance with the law (No. 96/2001 Coll. on Human Rights and Biomedicine and Act No. 101/2000 Coll. on the Protection of Personal Data) and the study was approved by the local institutional ethics committee of the Institute of Experimental Biology at Masaryk University, Brno, Czech Republic. The athletes were informed of the procedures and gave their informed written consent. Given the details provided, the participants consented to a breach of anonymity.

\section{Races}

A 35-year old female runner (Case 1) won the 24-h winter running race "Adidas 24 h on Lysá Mountain", which started on 25 January 2014 at 10:58 a.m. and finished on 26 January 2014 at 10:58 a.m. in Ostravice, Czech Republic. The lowest temperature was $-20.6^{\circ} \mathrm{C}$ and the highest $-7.9^{\circ} \mathrm{C}$, whereas the temperature at the top of Lysá Mountain was around $-19^{\circ} \mathrm{C}$. In addition, a gusty wind was blowing, which reduced the average perceived temperature down to $-28.9^{\circ} \mathrm{C}$ (25 January) and $-18.3^{\circ} \mathrm{C}$ (26 January). The average relative humidity was $88.5 \%$, the precipitation was $0.3 \mathrm{~mm}$ and the snow depth was 1 $\mathrm{cm}$. One lap measured $11.4 \mathrm{~km}$ and had $764 \mathrm{~m}$ of elevation.

A 38-year-old woman (Case 2) won the " $24 \mathrm{~h}$ Sri Chinmoy Self-Transcendence Race", the most important 24-h running race in the Czech Republic in 2012, which took place on 21-22 July 2012 in Kladno, starting at 12 p.m. and ending at 12 p.m. on the next day (15). The environmental conditions during the race were as follows: the maximum temperature was $18^{\circ} \mathrm{C}$; the minimum temperature was $10^{\circ} \mathrm{C}$ with an average ambient temperature of $12^{\circ} \mathrm{C}$. On average, $15 \mathrm{~mm}$ of precipitation was recorded and the average relative humidity changed from 58$94 \%$ over the duration of the race. The lap length was $1 \mathrm{~km}$, situated around an athletic stadium on asphalt with a $1 \mathrm{~m}$ elevation.

A 46-year-old female mountain biker won the "Czech Championship 24-h mountain biking race" in Jihlava (Case 3), a race with the highest number of participants from the series of 24-h mountain bike races held in the Czech Republic (14). The ultraendurance mountain bikers started at 12 p.m. on 18 May 2013 and finished at 12 p.m. on 19 May 2013. The maximum temperature was $30^{\circ} \mathrm{C}$, the minimum temperature was $6^{\circ} \mathrm{C}$ during the night at some places along the route, and the average temperature was $18^{\circ} \mathrm{C}$. No precipitation was recorded and the average relative humidity was $43 \%$ over the duration of the race. The course was comprised of a 9.5 $\mathrm{km}$ single-track with an elevation of $220 \mathrm{~m}$.

All athletes in the three races could consume food and beverages ad libitum. The only real difference between the three events was the number of times they had access to food/beverages due to varying circuit lengths. Fluid intake was estimated based on the athletes' reports. The amount of water in solid food was not recorded.

\section{Procedures}

All race participants including the present three cases completed self-reported pre- and post-race questionnaires. The questionnaires inquired about their age, sex, club membership, training during the three months prior to the race, hydration habits, drinking strategies during the race, use of medications and supplements, type of food consumed during the race, presence of luteal phase during the race, wearing knee compression socks, frequency of urination, post-race thirst and salt palatability, knowledge about EAH and post-race symptoms. After completing all data from the three races mentioned, we found that, interestingly, we had three female winners with a very mild EAH and they simultaneously reported the presence of the luteal phase during the race in the questionnaire. Therefore, we contacted them again via e-mail to ask them individually on the details of their menstrual cycles. None of the athletes were using any birth control medications. They all have an irregular menstrual cycle. They reported that they 
Table 1. Pre-race training parameters for Cases 1-3, RUN - running race; BIKE - mountain biking race

\begin{tabular}{lccc}
\hline & Case 1 & Case 2 & Case 3 \\
\hline Type of race & RUN & RUN & BIKE \\
Age (years) & 35 & 38 & 46 \\
Body height (cm) & 170.0 & 168.0 & 171.3 \\
Time as an active cyclist/runner (years) & 10 & 13 & 15 \\
Number of finished ultra-endurance marathons & 3 & 30 & 12 \\
Total weekly training time (h) & 12 & 15 & 12 \\
Weekly cycling/running training time (h) & 6 & 13 & 10 \\
Heart rate during training (b/min) & 130 & 140 & 125 \\
\hline
\end{tabular}

were in their luteal phase during the race and that this phase was not shorter than 10 days and not longer than 16 days from their ovulation to menstruation. Pre-race testing took place during the registration before the race between 7:00 and 11:00 a.m. in a private room adjacent to the registration area. No measurements were taken during the race. Post-race testing was performed at the same place between 12:00 and 1:00 p.m., immediately upon completing the race. All three athletes participated in a 24-h race, so the end of the race was at a similar time of the day $24 \mathrm{~h}$ later. All races were held in the Czech Republic and we were present at the measurements. Two races finished at 12 p.m., one finished at 10:58 a.m. The athletes could start a new round even one minute before the end of the race and consequently finish much later than the other athletes. Nevertheless, they could still be the best finishers due to a higher number of completed kilometers. Case 1 used this opportunity and thus finished among the last athletes nearly before 12 p.m. and she took all the measurements after 12 p.m. The athletes came to our site of measurement immediately after finishing the race and blood samples were taken accordingly. The three cases presented here underwent measurement and provided samples between 12 p.m. and 1 p.m., so it was within one hour after they completed the race despite various races on different dates and in different places. The athletes waiting for post-race measurements were not eating or drinking. Body mass was measured using a calibrated commercial scale (Tanita BC-351, Tanita Corporation of America, Inc.) to the nearest $0.1 \mathrm{~kg}$. Subjects were barefoot and generally clothed in running/cycling attire for both the pre- and post-race measurements and participants were advised to void their urinary bladder prior to the measurements. Body height was determined using a stadiometer (TANITA HR 001, Tanita Europe B.V. Amsterdam, The Netherlands). Blood and urine samples were taken at the same time as the anthropometric measurements. After venipuncture of an antecubital vein, one
Sarstedt S-Monovette (plasma gel, $7.5 \mathrm{ml}$ ) for chemical analysis and one Sarstedt S-Monovette (EDTA, $2.7 \mathrm{ml}$ ) for hematological analysis were collected, cooled, sent to the laboratory and analysed within six hours. Hematocrit was determined using Sysmex XE 2100 (Sysmex Corporation, Japan), plasma $\left[\mathrm{Na}^{+}\right]$, plasma urea on a Roche Modular Analytics (SWA), Modules P\& ISE (Hitachi High Technologies Corporation, Japan, Roche Diagnostic), and plasma osmolality using Arkray Osmotation (Arkray Factory, Inc., Japan). Samples of urine were collected in one Sarstedt monovette for urine $(10 \mathrm{ml})$ and sent to the laboratory. Urine urea was determined using a Roche Modular Analytics (SWA), Modules P\& ISE (Hitachi High Technologies Corporation, Japan, Roche Diagnostic), urine specific gravity $\left(\mathrm{U}_{\mathrm{sg}}\right)$ using $\mathrm{Au}$ Max-4030 (Arkray Factory, Inc., Japan), and urine osmolality using Arkray Osmotation (Arkray Factory, Inc., Japan). Potassium/sodium $\left(\mathrm{K}^{+} / \mathrm{Na}^{+}\right)$ratio in urine was calculated. Trans-tubular potassium gradient (TTKG) was calculated using the formula (potassium urine $\times$ osmolality $\left._{\text {serum }}\right) /\left(\right.$ potassium $_{\text {serum }} \times$ osmolality $\left._{\text {urine }}\right)(67)$. Glomerular filtration rate (GFR) was calculated using the formula of Levey et al. (49). Relative changes in plasma volume were calculated from preand post-race values of hematocrit and hemoglobin based on the equation of Strauss et al. (63). Creatinine clearance was calculated using the CockcroftGault formula (18).

\section{Results}

Age, body height and pre-race training parameters of each case (Cases 1-3) are presented in Table 1, body mass changes and laboratory blood parameters in Table 2 and Table 3, urinary parameters and calculations based on blood parameters in Table 3 .

Case 1

The athlete of Case 1 was not a member of 
Table 2. Laboratory results for Cases 1-3

\begin{tabular}{|c|c|c|c|c|}
\hline & Pre-race & Post-race & Absolute change & Relative change $(\%)$ \\
\hline \multicolumn{5}{|c|}{ Body mass (kg) } \\
\hline Case 1 & 60.8 & 61.3 & +0.5 & +0.8 \\
\hline Case 2 & 54.6 & 53.2 & -1.4 & -2.6 \\
\hline Case 3 & 64.3 & 62.3 & -2.0 & -3.1 \\
\hline \multicolumn{5}{|c|}{ Hematocrit (\%) } \\
\hline Case 1 & 39.0 & 36.0 & -3.0 & -7.7 \\
\hline Case 2 & 42.0 & 38.0 & -4.0 & -9.5 \\
\hline Case 3 & 38.0 & 35.0 & -3.0 & -7.9 \\
\hline \multicolumn{5}{|c|}{ Hemoglobin $(\mathrm{g} / \mathrm{dl})$} \\
\hline Case 1 & 131.0 & 125.0 & -6.0 & -4.6 \\
\hline Case 2 & 141.0 & 129.0 & -12.0 & -8.5 \\
\hline Case 3 & 123.0 & 115.0 & -8.0 & -6.5 \\
\hline \multicolumn{5}{|c|}{ 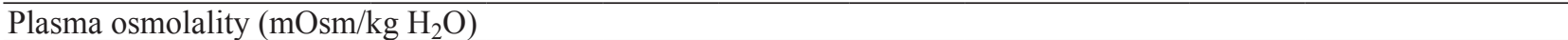 } \\
\hline Case 1 & 283.0 & 281.0 & -2.0 & -0.7 \\
\hline Case 2 & 282.0 & 279.0 & -3.0 & -1.1 \\
\hline Case 3 & 281.0 & 278.0 & -3.0 & -1.1 \\
\hline \multicolumn{5}{|c|}{ Plasma sodium $(\mathrm{mM})$} \\
\hline Case 1 & 136.0 & 134.0 & -2.0 & -1.5 \\
\hline Case 2 & 137.0 & 133.0 & -4.0 & -2.9 \\
\hline Case 3 & 139.0 & 134.0 & -5.0 & -3.6 \\
\hline \multicolumn{5}{|c|}{ Plasma potassium (mM) } \\
\hline Case 1 & 4.7 & 4.1 & -0.6 & -12.8 \\
\hline Case 2 & 6.5 & 4.6 & -1.9 & -29.2 \\
\hline Case 3 & 4.6 & 4.6 & 0 & 0 \\
\hline \multicolumn{5}{|c|}{ Plasma urea $(\mathrm{mM})$} \\
\hline Case 1 & 5.2 & 6.5 & +1.3 & +25.0 \\
\hline Case 2 & 4.1 & 10.4 & +6.3 & +153.7 \\
\hline Case 3 & 4.8 & 9.6 & +4.8 & +100.0 \\
\hline \multicolumn{5}{|c|}{ Plasma creatinine $(\mu \mathrm{M})$} \\
\hline Case 1 & 70.7 & 70.7 & 0 & 0 \\
\hline Case 2 & 70.6 & 79.5 & +8.9 & +12.6 \\
\hline Case 3 & 79.6 & 106.1 & +26.5 & +33.3 \\
\hline \multicolumn{5}{|c|}{ Plasma creatine kinase $(\mathrm{U} / \mathrm{l})$} \\
\hline Case 1 & 109.6 & $10,742.5$ & $+10,632.9$ & $+9,701.6$ \\
\hline Case 2 & 132.3 & $15,443.1$ & $+15,310.8$ & $+11,572.8$ \\
\hline Case 3 & 147.1 & 335.3 & +188.2 & +127.9 \\
\hline \multicolumn{5}{|c|}{ Creatinine clearance } \\
\hline Case 1 & 166.7 & 168.1 & +1.4 & +0.8 \\
\hline Case 2 & 145.4 & 126.2 & -19.2 & -13.2 \\
\hline Case 3 & 140.5 & 102.0 & -38.5 & -27.4 \\
\hline
\end{tabular}

any sports club. She reported that she had never heard about EAH and she did not know any causes or consequences of EAH. The runner planned her hydration regime before and after the race but did not have any drinking strategy during the race. She drank 11 of fluids an hour before the race. She took no medications pre-race. She reported that she had never heard about how to drink during the race, and that her drinking strategy during the race is determined by temperature. She did not know what volume of drinks is offered in the aid station and she planned to drink only water. The runner consumed sports drinks, tea with honey and three ampoules of magnesium. She drank approximately 9.61 during the $24 \mathrm{~h}(0.16 \mathrm{l} / \mathrm{kg} / \mathrm{h})$. Her plasma volume increased by $10 \%$. During the race, she ate bananas, rolls with cheese and ham, muesli bars, protein bars and sports gels. She did not use official food and fluids, her support forced her to eat after every lap. She wore knee compression socks during the race and took four ibalgins (nonsteroidal anti-inflammatory drugs, NSAIDs). The presence of luteal phase during the race was reported. She had problems with breathing and felt cold during the race in extremely cold winter conditions. She urinated twice during the race. The female runner finished the race with 10 laps, 
Table 3. Urine and blood parameters for Cases 1-3, NM - not measured

\begin{tabular}{|c|c|c|c|c|}
\hline & Pre-race & Post-race & Absolute change & Relative change $(\%)$ \\
\hline \multicolumn{5}{|c|}{ Urine specific gravity $(\mathrm{g} / \mathrm{ml})$} \\
\hline Case 1 & 1.026 & 1.017 & -0.009 & -0.9 \\
\hline Case 2 & 1.010 & 1.025 & +0.015 & +1.5 \\
\hline Case 3 & 1.007 & 1.027 & +0.020 & +2.0 \\
\hline \multicolumn{5}{|c|}{ Urine sodium (mM) } \\
\hline Case 1 & 134.0 & 10.0 & -124.0 & -92.5 \\
\hline Case 2 & 54.0 & 68.0 & +14.0 & +25.9 \\
\hline Case 3 & 37.0 & 55.0 & +18 & +48.6 \\
\hline \multicolumn{5}{|c|}{ Urine potassium $(\mathrm{mM})$} \\
\hline Case 1 & 65.4 & 31.8 & -33.6 & -51.4 \\
\hline Case 2 & 30.4 & 57.9 & +27.5 & +90.5 \\
\hline Case 3 & 6.4 & 47.9 & +41.5 & +648.4 \\
\hline \multicolumn{5}{|c|}{$\mathrm{K}^{+} / \mathrm{Na}^{+}$ratio in urine $(\mathrm{mM})$} \\
\hline Case 1 & 0.5 & 3.2 & +2.7 & +540.0 \\
\hline Case 2 & 0.6 & 0.9 & +0.3 & +50.0 \\
\hline Case 3 & 0.2 & 0.9 & +0.7 & +350.0 \\
\hline \multicolumn{5}{|c|}{ Glomerular filtration rate } \\
\hline Case 1 & 138.2 & 138.3 & +0.1 & +0.1 \\
\hline Case 2 & 135.6 & 122.4 & -13.2 & -9.7 \\
\hline Case 3 & 120.4 & 93.7 & -26.7 & -22.2 \\
\hline \multicolumn{5}{|c|}{ Trans-tubular potassium gradient } \\
\hline Case 1 & 34.2 & 9.4 & -24.8 & -72.5 \\
\hline Case 2 & 4.4 & 31.3 & +26.9 & +611.4 \\
\hline Case 3 & 0.8 & 27.6 & +26.8 & +3350.0 \\
\hline \multicolumn{5}{|c|}{ Urine osmolality $\left(\mathrm{mOsm} / \mathrm{kg} \mathrm{H}_{2} \mathrm{O}\right)$} \\
\hline Case 1 & 695.0 & 340.0 & 355.0 & -51.1 \\
\hline Case 2 & 263.0 & 693.0 & +430.0 & +163.5 \\
\hline Case 3 & 153.0 & 737.0 & +584.0 & +381.7 \\
\hline \multicolumn{5}{|c|}{ Urine urea $(\mathrm{mM})$} \\
\hline Case 1 & 343.9 & 208.0 & -135.9 & -39.5 \\
\hline Case 2 & NM & NM & NM & NM \\
\hline Case 3 & 40.0 & 465.9 & +425.9 & +1064.8 \\
\hline
\end{tabular}

achieving a total of $116 \mathrm{~km}$ with an average speed 5.6 $\mathrm{km} / \mathrm{h}$ and was declared the winner in the women's category. In the absolute order including women and men, she was placed fifteenth. She had blisters on her feet and she did not feel thirsty post-race. Her post-race salt palatability was number 3 on the scale from 0 to 10 . She consumed soup, tea, chicken and coffee during the first six hours after the race.

\section{Case 2}

The athlete of Case 2 was a member of a sports club. She had never heard about EAH and did not know any causes or consequences of EAH. She reported not having any plan for how to drink before, during and after the race; however, she had knowledge on how to drink during the race acquired from magazines. She reported a fluid consumption of 0.51 one hour prior to the race start. Temperature was the primary factor determining her drinking strategy during the race. She knew the volume of drinks offered in the aid station and planned to drink both water and sports drinks. The athlete was accompanied by her colleague who regularly attended her races. The estimated fluid intake was approximately 181 over the $24 \mathrm{~h}(0.33 \mathrm{l} / \mathrm{kg} / \mathrm{h})$. Her plasma volume increased by $16.8 \%$. Her fluid consumption consisted of water, hot tea, sports drinks, Coca-Cola and soup. The athlete did not exactly report her food intake. However, she regularly ate a little every lap, for instance potatoes, salt crackers, tomatoes, bread with ham and cheese and butter, rice, fruit and rarely sports gels. The athlete used the official race buffet and her own food and fluid supplies. The majority of drinks were consumed during the last six hours of the race. She reported urinating three times during the race, twice of which were during the last six hours of the race. She took no medications prior to or during the race. The presence of luteal phase during the race was re- 
ported. The athlete did not wear compression socks during the race. She finished the race with the total distance of $220.1 \mathrm{~km}$ and an average speed of 9.2 $\mathrm{km} / \mathrm{h}$. She won not only the women's category, but was also declared the overall winner of the race across all categories. The second placed woman achieved $189.5 \mathrm{~km}$ with an average speed of 7.9 $\mathrm{km} / \mathrm{h}$ and the first man $213.8 \mathrm{~km}$ with an average speed of $9.0 \mathrm{~km} / \mathrm{h}$. She felt thirsty post-race and consumed soup, tea and Coca-Cola during the first six hours after the race. Her post-race salt palatability was number 4 on the scale from 0 to 10 . She denied taking any NSAIDs during or after the race. The athlete had no blisters on her feet post-race. She complained of headache, flushing, irritability, myalgia and feet swelling post-race.

\section{Case 3}

The athlete was a member of a sports club. She had heard about EAH, but did not know about its causes and consequences. She reported no pre-, mid- or post-race drinking plan. She reported a 0.6 1 fluid intake in the last hour before the race. Her drinking strategy during the race was determined primarily by temperature and then by thirst. She did not know the volume of the drinks offered at the official aid stations. The mountain biker planned to drink only sports drinks and Coca-Cola. She took no medications pre-race. The athlete was without any accompaniment and primarily utilised her own supplies at the pit stop and occasionally consumed from the official aid station. She drank approximately $9.60 \mathrm{l}$ of fluids during the $24 \mathrm{~h}(0.15 \mathrm{l} / \mathrm{kg} / \mathrm{h})$. Her plasma volume increased by $12.1 \%$. She reported urinating three times during the race, once during each of the first three quarters of the race, none in the last one. She drank sports drinks and Coca-Cola, and her food consumption consisted of bananas, soup, potatoes, chips, salt biscuits, sports gels, sports bars and rolls with ham and cheese. The mountain biker reported using salt tablets and caffeine tablets, ergogenic supplements with a preference for branchedchain amino acids (BCAA) and magnesium products. The presence of luteal phase during the race was reported. She did not wear compression socks. The athlete won in the women's category and was placed sixteenth overall across categories. The total distance covered was $332.5 \mathrm{~km}$, yielding an average velocity of $16.1 \mathrm{~km} / \mathrm{h}$. The second placed woman achieved $304.0 \mathrm{~km}$ with an average speed of 14.7 $\mathrm{km} / \mathrm{h}$. The athlete had one episode of mild diarrhoea in the middle of the race. She felt thirsty and hungry post-race. Her post-race salt palatability was number 8 on the scale from 0 to 10 . The athlete consumed ham, melon, oranges, muesli bars, Coca-
Cola and water during the first six hours post-race. She had no blisters on her feet post-race. She denied taking any NSAIDs during or after the race. After completing the 24-h race, the athlete did not report any symptoms associated with it, except for fatigue.

\section{Discussion}

The interesting finding was that all three female athletes, who were examined in the present study, competed successfully and won a $24-\mathrm{h}$ race, were faster than any other female competitors in their races and were mildly hyponatremic post-race, despite the different environmental conditions of each race.

\section{Sex, Pre-Race Training, Race Performance, Fluid Intake, Post-Race Symptoms and EAH}

Sex-hormones may influence fluid balance parameters during the luteal phase of the menstrual cycle $(57,66)$ and all three female athletes competed during the ten days of their luteal phase of the menstrual cycle. According to a statement of the Third International Exercise-associated Hyponatremia Consensus Development Conference (31), smaller individuals are more likely to develop EAH adjusted for the BMI and racing time, but sex difference was not statistically significant (8). Furthermore, female marathoners drank more fluid in proportion to their body size, were significantly lighter and ran slower than male runners according to Hew et al. (26). Slow running performance is another risk factor $(10,31)$ for the development of EAH; however, all three female ultra-endurance athletes achieved an excellent race performance, were among the fastest finishers in their races across all categories and were the overall winners of female categories. Another risk of EAH occurrence is event inexperience or inadequate training (31).

Nevertheless, older age, veteran hobby category, long previous experience in the particular sport, a large number of years as an active runner (Cases 1 and 2) or biker (Case 3) and self-reported weekly training hours in pre-race applications were common in each case. Similarly, the ultra-endurance runners in the study of Cairns and Hew-Butler (10) were also experienced; however, 10 out of 15 developed EAH during the race, and 4 out of 15 post-race. By contrast, it is worth mentioning that none of the three female athletes knew about the causes and consequences of EAH and, unlike Case 2, Cases 1 and 3 had never heard about EAH. The underlying pathophysiology of EAH involves overhydration due to an excessive intake of water, sports drinks, other hypotonic beverages $(8,31,52)$ and readily available fluids (31). All three athletes reported not having 
any drinking plan during the race and pointed out temperature as the primary factor influencing their drinking strategy during the race. However, we must consider different environmental conditions in each race. Fluid consumption was $0.50 \mathrm{l} / \mathrm{h}$ in a cold weather winter ultra-distance race in Alaska (65) and a decreased serum $\left[\mathrm{Na}^{+}\right]$concentration was due to fluid overload caused by excessive fluid consumption.

Unfortunately, we did not measure sweat rates under various conditions with the intent to find the appropriate amount of fluid to replace sweat losses during the race in each case and we did not record the amount of fluid in solid food. The occurrence of non-specific symptoms was unique in each case and none of the three athletes was admitted to an emergency department post-race. Similarly, in their recent study Cairns and Hew-Butler (11) propose that symptoms of EAH are more common than previously thought, and that the symptoms are documented in both hyponatremic and normonatremic athletes. To summarize, fast and experienced athletes can also be susceptible to developing EAH. We suggest that relative over-drinking of hypotonic fluids, emotional stress associated with fighting for the winning position in all three cases, uncomfortable environment, sleep deprivation (24-h race) and sex hormones as nonosomotic stimuli for the secretion of non-osmotic arginine vasopressin (AVP) (57) might have contributed to the occurrence of EAH in the athletes.

\section{Changes in Body Mass, Urine Specific Gravity and EAH}

Another major risk factor for the development of EAH is body mass gain during exercise (31). If we use cut-off points for hydration state based upon changes in body mass by Noakes et al. (52), Case 1 was overhydrated, Case 2 was euhydrated and Case 3 was dehydrated post-race. Body mass that is equal to or above the individual normal body mass as in Case 1 is a positive indicator for the presence of fluid overload (31). Body mass loss and post-race $\mathrm{U}_{\mathrm{sg}}$ of $>1.020 \mathrm{mg} / \mathrm{l}$ in Case 2 and Case 3 indicate hypohydration rather than hyperhydration according to Kavouras (38). However, $\mathrm{U}_{\mathrm{sg}}$ samples were considered within the normal range in all three cases according to Armstrong et al. (7). In addition, increased plasma urea and urine osmolality may suggest glycogen and intramyocellular lipid depletion in skeletal muscle (62) or transitory renal decline due to dehydration in Case 2 and Case 3. In a recent study of 887 finishers by Hoffman et al. (32), 18.5\% of the finishers were dehydrated, of which $35.6 \%$ had EAH. EAH can occur simultaneously with dehydration and cannot be predicted only by body mass changes (48). On the contrary, the use of post-race $\mathrm{U}_{\mathrm{sg}}$ concentration is also limited $(2,6,7)$. An in- crease in $\mathrm{U}_{\mathrm{sg}}$ often occurs due to muscle catabolism and elevated plasma urea during an ultra-endurance performance $(41,42)$ and/or protein digestion (25). Catabolic products of protein metabolism associated with physical strain (13) could be related to the increased urine osmolality in Case 2 and Case 3, which limits its potential utility for the assessment of dehydration. The incidence of EAH contributes to greater sodium loss through sweat under ambient temperature conditions and longer duration of the races, similarly as documented by Hoffman et al. (32). According to Hew et al. (31), we have evidence of hypovolemic EAH during ultra-endurance races, although the relative contribution of sweat and urine sodium loss is negligible with the possible exception of volume depletion with serum or plasma $\left[\mathrm{Na}^{+}\right]$ levels below $135 \mathrm{mM}$. Hypovolemic EAH can occur in races lasting over $20 \mathrm{~h}(32,34)$ with elevated blood urea nitrogen levels of $>20 \mathrm{mg} / \mathrm{dl}(17,55)$ and body mass loss $(11,32,34)$ also indicating volume depletion. Plasma urea increased to over $20 \mathrm{mg} / \mathrm{dl}$ and body mass decreased in both Case 2 and Case 3. However, hypovolemic EAH is also supported by urinary $\left[\mathrm{Na}^{+}\right]<30 \mathrm{mM}$ (11). Only Case 1, who gained body mass, showed post-race urinary $\left[\mathrm{Na}^{+}\right]<30 \mathrm{mM}$, but this was in contrast to other indicators suggesting dilutional EAH.

\section{Hematological Parameters, Plasma Urea, Plasma Creatinine and Plasma Creatine Kinase}

The common hematological and biochemical parameters, aside from a decreased plasma $\left[\mathrm{Na}^{+}\right]$and an increased plasma urea, were decreased hematocrit, decreased hemoglobin and increased plasma volume in all three cases. Hemodilution effects and plasma volume increase were reported by Knechtle et al. (46) in a 24-h running race, Fellmann et al. (19) during a 7-day endurance race and Neumayr et al. (51) in ultramarathon cycling. Hematocrit also significantly decreased in two studies on a cold ultra-endurance race $(64,65)$. Hemodilution, decreased plasma $\left[\mathrm{Na}^{+}\right]$ and plasma volume expansion indicated increased aldosterone activity (19) as well as an increase in $\operatorname{ADH}(51,52)$, which could lead to retention of free water.

An increased in plasma volume and plasma urea together with a decrease in hemoglobin and hematocrit might also be a result of transitory renal function impairment due to rhabdomyolysis (23). Cases 1 and 2 (ultra-endurance runners) both developed EAH and their plasma creatine kinase (CK) increased above $10,000 \mathrm{U} / 1$ suggesting rhabdomyolysis (29). Mild to moderate elevations of CK are common in long-distance runners and exertional rhabdomyolysis is often associated with EAH $(29,35)$. According to the Cairns 
and Hew-Butler study (11), transient hypovolemic EAH preceded significantly higher elevations in CK in their limited sample size of runners during an ultraendurance race. In our recent study (14), we documented $6 \%$ cases of EAH with rhabdomyolysis in ultra-endurance runners (five men and one woman) and $0 \%$ in ultra-endurance mountain bikers. Fellmann et al. (20) demonstrated that a 24-h running race caused more muscular lesions than a triathlon, where ultra-endurance cycling was a part of the event. Cycling involves predominantly concentric muscle activity, which does not lead to skeletal muscle damage in cyclists (44).

Rhabdomyolysis only rarely progresses to acute renal failure in endurance athletes (61). Temporal changes in GFR, plasma creatinine and plasma urea might lead to reduced renal functions in relation to natremic status (11) and may contribute to fluid overload with limited urinary excretion (11) in Case 2 and Case 3. In the study of Lipman et al. (50), acute renal injury was more prevalent in females and significantly associated with greater body mass loss during multi-stage ultra-endurance marathons, even though women lost less body mass than men. However, the "risk of acute kidney injury" defined as $1.5 \times$ baseline creatinine or "acute kidney injury" defined as $2 \times$ creatinine or a clinically relevant decrease in renal functions defined as $>25 \%$ decrease in GFR from baseline (58) was not observed in any of the athletes.

\section{Plasma and Urine $\left[\mathrm{Na}^{+}\right]$and $\left[\mathrm{K}^{+}\right]$, Plasma and Urine Osmolality and TTKG}

Sodium, potassium, and plasma and urine osmolality are indirect indicators of aldosterone and ADH activity (43). Plasma osmolality decreased by approximately one degree in all cases and did not decrease under the normal range of $275-295 \mathrm{mOsm} / \mathrm{kg}$ $\mathrm{H}_{2} \mathrm{O}$ (28). Osmotic homeostasis (i.e. 1-2\% deviation in plasma osmolality) (9) was maintained. According to Hew-Butler et al. (30) and Tam et al. (66), athletes are able to regulate plasma osmolality even when their body mass loss is combined with a total body water decrease (66). Furthermore, it is necessary to take into account that substrates constitute $95 \%$ of the total serum osmolality, and that the water content in a serum sample is less per unit volume (5). This fact increases the statistical variance and difficulty of interpreting plasma osmolality as a hydration index (5).

A mild pre-race hyperkalemia in Case 2 could suggest that $\left[\mathrm{K}^{+}\right]$secretion and aldosterone bioactivity were impaired and that the collecting tubule did not respond appropriately (68). Hyperkalemia or high potassium intake as a result of $\left[\mathrm{K}^{+}\right]$over- load or a shift of $\left[\mathrm{K}^{+}\right]$is associated with a higher TTKG (16). However, urine osmolality would be equal to or greater than plasma osmolality and $>300$ $\mathrm{mOsm} / \mathrm{kg} \mathrm{H}_{2} \mathrm{O}$ for a valid calculation of the TTKG (21). Pre-race level of urine osmolality was lower than plasma osmolality concentration in Case 2. Similarly, in Case 3 pre-race urine osmolality was nearly twice as low as plasma osmolality and the calculated pre-race TTKG fell below 3.0, which normally indicates a complete blockade of aldosterone bioactivity. This was presumably caused by inaccurate prerequisites for the TTKG calculation, as in Case 2. By contrast, post-race TTKG increased and was $>10$ in Cases 2 and 3, suggesting an increased activity of aldosterone $(16,22,67)$. TTKG decreased in Case 1 and was $<10$ post-race; however, the value was almost 10 . Moreover, for the calculation of TTKG urine $\left[\mathrm{Na}^{+}\right]$must be $>25 \mathrm{mM}$ (16) and post-race urine $\left[\mathrm{Na}^{+}\right]$was only $10 \mathrm{mM}$ Case 1 , thus the calculation might not be accurate as well. Therefore, we did not consider pre-race TTKG in Case 2 and Case 3 and post-race TTKG in Case 1 to be valid calculations. Nevertheless, the post-race $\mathrm{K}^{+} / \mathrm{Na}^{+}$ ratio in urine increased in all three cases. Increased urinary $\left[\mathrm{K}^{+}\right]$losses in Cases 2 and 3 indicate a response to the stimulation of the renin-angiotensin system, as shown in Knechtle et al. (43). The urinary free water conservation occurred in Case 2 and Case 3 , as shown by an increase in urine osmolality, and simultaneously urinary $\left[\mathrm{Na}^{+}\right]$losses, therefore we assume they have an inappropriate release of ADH in response to exercise (24).

This is in accordance with previous findings in hot conditions, where a significant negative correlation between performance times and urine osmolality results was observed (11). By contrast, urine osmolality decreased in Case 1 in a cold race, even though faster finishers had higher urine osmolarity in a cold race than slower finishers in Paulin et al. (56). The reason might be that the pre-race level of urine osmolality was nearly twice as high as the postrace level in Case 1. Nevertheless, urine osmolality reached a level indicating an inappropriate release of ADH in all three cases, including Case 1. The increased urine $\left[\mathrm{Na}^{+}\right]$excretion (natriuresis) in the presence of a low blood $\left[\mathrm{Na}^{+}\right]$concentration is paradoxical and is presumably due to the combined effects of increased AVP [58] and ANP in the blood (37). However, we did not measure these parameters. It is important to underline that the association of urinary $\left[\mathrm{Na}^{+}\right]$loss due to exercise-induced brain natriuretic peptide secretion and EAH is still unclear (30).

\section{Nonsteroidal Anti-Inflammatory Drugs and EAH}

We found no association between the reduction 
of GFR and the simultaneous ingestion of NSAIDs, which was in agreement with the study of Cairns and Hew-Butler (11). Case 3, who had the highest average percent decrease in GFR, did not ingest any NSAIDs, and neither did Case 2. The effects of using of NSAIDs remain unresolved $(11,33)$, although in a study of Cairns and Hew-Butler (10) seven out of 10 hyponatremic and none out of five normonatremic ultra-endurance runners consumed NSAIDs. There is a general belief that sodium supplementation prevents EAH. However, Hoffman and Myers (33) demonstrated that oral sodium supplementation does not necessarily prevent symptomatic EAH. Moreover, sodium supplementation is not recommended during exercise lasting less than $18 \mathrm{~h}$ (8). The hyponatremic Case 3 reported using salt tablets during the race; therefore, we may regard the use of salt supplements as not protective against EAH in the present study. Similar results were obtained in the study of Cairns and Hew-Butler (11), where six out of 10 hyponatremic athletes used salt supplements.

\section{Limitations}

We are aware that $\mathrm{U}_{\mathrm{sg}}$ is not a reliable predictor of hydration status; however, it was not possible to obtain data on sweat rates under the conditions of each race. Another limitation is the absence of data on the amount of water in the solid food consumed. Reliance on the athletes' responses in a questionnaire and self reported fluid intake is another potentional source of error in this research. Despite these limitations, the strength of the present study is that 24-h ultra-endurance events were considered under a variety of environmental conditions and that the study involved two sports disciplines (i.e. running and cycling).

\section{Conclusions and Practical Applications}

The three observed female athletes achieved a top performance (partially better than men) and developed mild biochemical EAH. Moreover, Case 1 and Case 2 showed elevated creatine kinase concentrations $>10,000 \mathrm{U} / 1$ with the absence of renal function abnormality. The common characteristics were female sex, veteran recreational category, long experience in the particular sports discipline, excellent race performance, similar total weekly training hours and the presence of luteal phase of the menstrual cycle during the race. Hematocrit and hemoglobin decreased and post-race $\mathrm{K}^{+} / \mathrm{Na}^{+}$ratio in urine increased in all three cases. In addition, an increased body mass and decreased urine specific gravity and urine osmolality suggested over-drinking in Case 1. A decrease in the glomerular filtration rate and creatine clearance accompanied by an increase in urine $\left[\mathrm{Na}^{+}\right]$may contribute to fluid overload in Case 2 and Case 3. Furthermore, urine osmolality reached a level indicating antidiuretic hormone secretion in all the present cases. Therefore, we recommend that race medical personnel should not forget to look for EAH even in fast and experienced female endurance athletes and during races in different environmental conditions.

\section{References}

1. Almond, C.S., Shin, A.Y., Fortescue, E.B., Mannix, R. and Wypij, D. Hyponatremia among runners in the Boston marathon. $N$. Engl. J. Med. 352: 1550-1556, 2005.

2. American College of Sports Medicine, Sawka, M.N., Burke, L.M., Eichner, E.R., Maughan, R.J., Montain, S.J. and Stachenfeld, N.S. American College of Sports Medicine Position Stand. Exercise and fluid replacement. Med. Sci. Sports Exerc. 39: 377-390, 2007.

3. Armstrong, L.E., Epstein, Y., Greenleaf, J.E., Haymes, E.M., Hubbard, R.W., Roberts, W.O. and Thompson, P.D. American College of sports medicine position stand. Heat and cold illnesses during distance running. Med. Sci. Sports Exerc. 28: 39-60, 1996.

4. Armstrong, L.E., Johnson, E.C., Ganio, M.S., Judelson, D.A., Vingren, J.L., Kupchak, B.R., Kunces, L.J., Muñoz, C.X., McKenzie, A.L. and Williamson, K.H. Effective body water and body mass changes during summer ultra-endurance road cycling. $J$. Sports Sci. 33: 125-135, 2015.

5. Armstrong, L.E., Maughan, R.J., Senay, L.C. and Shirreffs, S.M. Limitations to the use of plasma osmolality as a hydration biomarker. Am. J. Clin. Nutr. 98: 503-504, 2013.

6. Armstrong, L.E., Pumerantz, A.C., Fiala, K.A., Roti, M.W., Kavouras, S.A., Casa, D.J. and Maresh, C.M. Human hydration indices: Acute and longitudinal reference values. Int. J. Sport Nutr. Exerc. Met. 20: 145-153, 2010.

7. Armstrong, L.E., Soto, J.A.H., Hacker, F.T., Casa, D.J., Kavouras, S.A. and Maresh, C.M. Urinary indices during dehydration, exercise and rehydration. Int. J. Sport Nutr. 8: 345-355, 1998.

8. Bennett, B.L., Hew-Butler, T., Hoffman, M.D., Rogers, I.R. and Rosner, M.H. Wilderness Medical Society: Wilderness medical society practice guidelines for treatment of exercise-associated hyponatremia. Wilderness Environ. Med. 24: 228-240, 2013.

9. Bourque, C.W. Central mechanisms of osmosensation and systemic osmoregulation. Natl. Rev. Neurosci. 9: 519-531, 2008.

10. Cairns, R.S. and Hew-Butler, T. Incidence of exercise-associated hyponatremia and its association with nonosmotic stimuli of arginine vasopressin in the GNW100s ultra-endurance marathon. Clin. J. Sport Med. 25: 347-354, 2014.

11. Cairns, R.S. and Hew-Butler, T. Proof of concept: hypovolemic hyponatremia may precede and augment creatine kinase elevations during an ultramarathon. Eur. J. Appl. Physiol. 116: 647655, 2016.

12. Casa, D.J., Stearns, R.L., Lopez, R.M., Ganio, M.S., McDermott, B.P., Yeargin, S.W., Yamamoto, L.M., Mazerolle, S.M., Roti, M.W., Armstrong, L.E. and Maresh, C.M. Influence of hydration on physiological function and performance during trail running in the heat. J. Athl. Train. 45: 147-156, 2010.

13. Cheuvront, S.N., Kenefick, R.W., Charkoudian, N. and Sawka, M.N. Physiologic basis for understanding quantitative dehydration. Am. J. Clin. Nutr. 97: 455-462, 2013.

14. Chlíbková, D., Knechtle, B., Rosemann, T., Tomášková, I., Novotný, J., Žákovská, A. and Uher, T. Rhabdomyolysis and exercise-associated hyponatremia in ultra-bikers and ultra-runners. $J$. 
Int. Soc. Sports Nutr. 12: 1-12, 2015

15. Chlíbková, D., Knechtle, B., Rosemann, T., Žákovská, A. and Tomášková, I. The prevalence of exercise-associated hyponatremia in 24-h ultra-mountain bikers, 24-h ultra-runners and multi-stage ultra-mountain bikers in the Czech Republic. J. Int. Soc. Sports Nutr. 11: 1-17, 2014.

16. Choi, M.J. and Ziyadehm F.N. The utility of the transtubular potassium gradient in the evaluation of hyperkalemia. J. Am. Soc. Nephrol. 19: 424-426, 2008.

17. Chung, H.M., Kluge, R., Schrier, R.W. and Anderson R.J. Clinical assessment of extracellular fluid volume in hyponatremia. Am. J. Med. 83: 905-908, 1987.

18. Cockcroft, D.W. and Gault, M.H. Prediction of creatinine clearance from serum creatinine. Nephron. 16: 31-41, 1976.

19. Fellmann, N., Ritz, P., Ribeyre, J., Beaufrère, B., Delaître, M. and Coudert, J. Intracellular hyperhydration induced by a 7-day endurance race. Eur. J. Appl. Physiol. Occup. Physiol. 80: 353$359,1999$.

20. Fellmann, N., Sagnol, M., Bedu, M., Falgairette, G., Van Praagh, E., Gaillard, G., Jouanel, P. and Coudert, J. Enzymatic and hormonal responses following a $24 \mathrm{~h}$ endurance run and a $10 \mathrm{~h}$ triathlon race. Eur. J. Appl. Physiol. 57: 545-553, 1988.

21. Field, M.J., Stanton, B.A. and Giebisch, G.H. Influence of ADH on renal potassium handling: A micropuncture and microperfusion study. Kidney Int. 25:502-511, 1984.

22. Freund, B.J., Shizuru, E.M., Hashiro, G.M. and Claybaugh, J.R. Hormonal, electrolyte, and renal responses to exercise are intensity dependent. J. Appl. Physiol. 70: 900-906, 1991.

23. Gastmann, U., Dimeo, F., Huonker, M., Böcker, J., Steinacker, J.M., Petersen, K.G., Wieland, H., Keul, J. and Lehmann, M. Ultratriathlon-related blood-chemical and endocrinological responses in nine athletes. J. Sport. Med. Phys. Fit. 38: 18-23, 1998.

24. Gross, P. Clinical management of SIADH. Ther. Adv. Endocrinol. Metab. 3: 61-73, 2012.

25. Hamouti, N., Del Coso, J., Avila, A. and Mora-Rodrigues, R. Effects of athletes' muscle mass on urinary markers of hydration status. Eur. J. Appl. Physiol. 109: 213-219, 2010.

26. Hew, T.D. Women hydrate more than men during a marathon race: hyponatremia in the Houston marathon: a report on 60 cases. Clin. J. Sport Med. 15: 148-153, 2005.

27. Hew, T.D., Chorley, J.N., Cianca, J.C. and Divine, J.G. The incidence, risk factors, and clinical manifestation of hyponatremia in marathon runners. Clin. J. Sport Med. 13: 41-47, 2003.

28. Hew-Butler, T. Arginine vasopressin, fluid balance and exercise. Is exercise-associated hyponatremia a disorder of arginine vasopressin secretion? Sports Med. 40: 459-479, 2010.

29. Hew-Butler, T. Hyponatremia, rhabdomyolysis, and renal failure. Marathon Beyond. 17: 70-80, 2013.

30. Hew-Butler, T., Jordaan, E., Stuempfle, K.J., Speedy, D.B., Siegel, A.J., Noakes, T.D., Soldin, S.J. and Verbalis, J.G. Osmotic and nonosmotic regulative of arginine vasopressin during prolonged endurance exercise. J. Clin. Endocrinol. Metab. 93: 2072-2078, 2008.

31. Hew-Butler, T.D., Rosner, M.H., Fowkes-Godek, S., Dugas, J.P., Hoffman, M.D., Lewis, D.P., Maughan, R.J., Miller, K.C., Montain, S.J., Rehrer, N.J., Roberts, W.O., Rogers, I.R., Siegel, A.J., Stuempfle, K.J., Winger, J.M. and Verbalis, J.G. Statement of the Third International Exercise-associated Hyponatremia Consensus Development Conference, Carlsbad, California. Clin. J. Sport Med. 25: 303-320, 2015.

32. Hoffman, M.D., Hew-Butler, T. and Stuempfle, K.J. Exerciseassociated hyponatremia and hydration status in 161-km ultramarathoners. Med. Sci. Sports Exerc. 45: 784-791, 2013.

33. Hoffman, M.D. and Myers, T.M. Case study: Symptomatic exercise-associated hyponatremia in an endurance runner despite sodium supplementation. Int. J. Sport. Nutr. Exerc. Met. 25: 603606, 2015.
34. Hoffman, M.D., Stuempfle, K.J., Rogers, I.R., Weschler, L. and Hew-Butler, T. Hyponatremia in the 2009 161-km Western States Endurance Run. Int. J. Sports Physiol. Perform. 7: 6-10, 2012.

35. Hoffman, M.D., Stuempfle, K.J., Sullivan, K. and Weiss, R.H. Exercise-associated hyponatremia with exertional rhabdomyolysis: importance of proper treatment. Clin. Nephrol. 83: 235-242, 2015.

36. Irving, R.A., Noakes, T.D., Irving, G.A. and Van Zyl-Smit, R. The immediate and delayed effects of marathon running on renal function. J. Urol. 36: 1176-1180, 1986.

37. Kamoi, K., Ebe, T., Kobayashi, O., Ishida, M., Sato, F., Arai, O., Tamura, T., Takagi, A., Yamada, A., Ishibashi, M. et al. Atrial natriuretic peptide in patients with the syndrome of inappropriate antidiuretic hormone secretion and with diabetes insipidus. $J$. Clin. Endocrinol. Metab. 70: 1385-1390, 1990.

38. Kavouras, S.A. Assessing hydration status. Curr. Opin. Clin. Nutr. Metab. Care. 5: 519-524, 2002.

39. Kawai, N., Baba, A., Suzuki, T. and Shiraishi, H. Roles of arginine vasopressin and atrial natriuretic peptide in polydipsiahyponatremia of schizophrenic patients. Psych. Res. 101: 39-45, 2001.

40. King, R.F.G.J., Cooke, S., Carroll, S. and O'Harra, J. Estimating changes in hydration status from changes in body mass: consideration regarding metabolic water and glycogen storage. J. Sports Sci. 26: 1361-1363, 2008.

41. Knechtle, B., Knechtle, P. and Kohler, G. The effects of 1,000 $\mathrm{km}$ nonstop cycling on fat mass and skeletal muscle mass. Res. Sports. Med. 9: 170-185, 2011.

42. Knechtle, B., Knechtle, P., Rosemann, T. and Oliver, S. A Triple Iron triathlon leads to a decrease in total body mass but not to dehydration. Res. Q. Exerc. Sport. 81: 319-327, 2010.

43. Knechtle, B., Knechtle, P., Rüst, C.A., Gnädinger, M., Imoberdorf, R., Kohler, G., Rosemann, T. and Ballmer, P. Regulation of electrolyte and fluid metabolism in multi-stage ultra-marathoners. Horm. Metab. Res. 44: 919-926, 2012.

44. Knechtle, B., Wirth, A., Knechtle, P. and Rosemann, T. An ultracycling race leads to no decrease in skeletal muscle mass. Int. $J$. Sports Med. 30: 163-167, 2009.

45. Knechtle, B., Wirth, A., Knechtle, P. and Rosemann, T. Increase of total body water with decrease of body mass while running $100 \mathrm{~km}$ nonstop - formation of edema? Res. Q. Exerc. Sport. 80: 593-603, 2009.

46. Knechtle, B., Wirth, A., Knechtle, P., Rosemann, T. and Senn, O. Do ultra-runners in a 24-h run really dehydrate? Ir. J. Med. Sci. 180: 129-134, 2011.

47. Knechtle, B., Zing, M.A., Knechtle, P., Rosemann, T. and Rüst, C.A. Feet swelling in a multistage ultraendurance triathlete: a case study. Int. J. Gen. Med. 8: 325-332, 2015.

48. Lebus, D.K., Casazza, G.A., Hoffman, M.D. and Van Loan, M.D. Can changes in body mass and total body water accurately predict hyponatremia after a $161-\mathrm{km}$ running race? Clin. J. Sport Med. 20: 193-199, 2010.

49. Levey, A.S., Bosh, J.P., Lewis, J.B., Greene, T., Rogers, N. and Roth, D. A more accurate method to estimate glomerular filtration rate from serum creatinine: a new prediction equation. Modification of diet in renal disease study group. Ann. Intern. Med. 130: 461-470, 1999.

50. Lipman, G.S., Krabak, B.J., Rundell, S.D., Shea, K.M., Badows$\mathrm{ki}, \mathrm{N}$. and Little, C. Incidence and prevalence of acute kidney injury during multistage ultramarathons. Clin. J. Sport. Med. 26: 314-319, 2016.

51. Neumayr, G., Pfister, R., Hoertnagl, H., Mitterbauer, G., Prokop, W. and Joannidis, M. Renal function and plasma volume following ultramarathon cycling. Int. J. Sports Med. 26: 2-8, 2005.

52. Noakes, T. Waterlogged. The serious problem of overhydration in endurance sports. New Zealand: Human Kinetics, 2012. 
53. Noakes, T.D., Sharwood, K., Speedy, D., Hew, T., Reid, S., Dugas, J., Almond, C., Wharam, P. and Weschler, L. Three independent biological mechanisms cause exercise-associated hyponatremia: evidence from 2, 135 weighed competitive athletic performances. Proc. Natl. Acad. Sci. USA. 102: 18550-18555, 2005 .

54. Nolte, H.W., Noakes, T.D. and Van Vuuren, B. Protection of total body water content and absence of hyperthermia despite $2 \%$ body mass loss (,voluntary dehydration“) in soldiers drinking ad libitum during prolonged exercise in cool environmental conditions. Brit. J. Sports Med. 45: 1106-1112, 2011.

55. Owen, B.E., Rogers, I.R., Hoffman, M.D., Stuempfle, K.J., Lewis, D., Fogard, K., Verbalis, J.G. and Hew-Butler, T. Efficacy of oral versus intravenous hypertonic saline in runners with hyponatremia. J. Sci. Med. Sport. 17: 457-462, 2014.

56. Paulin, S., Roberts, J., Roberts, M. and Davis, I. A case study evaluation of competitors undertaking an antarctic ultra-endurance event: nutrition, hydration and body composition variables. Extrem. Physiol. Med. 4: 3, 2015.

57. Pearce, E.A., Myers, T.M. and Hoffman, M.D. Three case of severe hyponatremia during a river run in Grand Canyon National Park. Wilderness Environ. Med. 26: 189-195, 2015.

58. Ricci, Z., Cruz, D.N. and Ronco, C. Classification and staging of acute kidney injury: beyond the Rifle and AKIN criteria. Nat. Rev. Nephrol. 7: 201-208, 2011.

59. Roberts, W.O. Heat and cold. What does the environment do to marathon injury? Sports Med. 37: 400-403, 2007.

60. Rosner, M.H. Exercise-associated hyponatremia. Semin. Nephrol. 29: 271-281, 2009

61. Sinert, R., Kohl, L., Rainone, T. and Scalea, T. Exercise-induced rhabdomyolysis. Ann. Emerg. Med. 23: 1301-1306, 1994.

62. Stellingwerff, T., Boon, H., Jonkers, R.A., Senden, J.M., Spriet, L.L., Koopman, R. and van Loon, L.J. Significant intramyocellular lipid use during prolonged cycling in endurance-trained males as assessed by three different methodologies. Am. J. Physiol. 292: E1715-E1723, 2007.

63. Strauss, M.B., Davis, R.K., Rosenbaum, J.D. and Rossmeisl, E.C. Water diuresis produced during recumbency by the intravenous infusion of isotonic saline solution. J. Clin. Invest. 30: 862-868, 1951.

64. Stuempfle, K.J., Lehmann, D.R., Case, H.S., Bailey, S., Hughes, S.L., McKenzie, J. and Evans, D. Hyponatremia in a cold weather ultraendurance race. Alaska Med. 44: 51-55, 2002.

65. Stuempfle, K.J., Lehmann, D.R., Case, H.S., Hughes, S.L. and Evans, D. Change in serum sodium concentration during a cold weather ultradistance race. Clin. J. Sport. Med. 13: 171-175, 2003.

66. Tam, N., Hew-Butler, T., Papadopoulou, E., Nolte, H. and Noakes, T.D. Fluid intake and changes in blood chemistry, running speed and body mass during an $80 \mathrm{~km}$ mountain trail race. Med. Sport. 13: 108-115, 2009.

67. West, M.L., Marsden, P.A., Richardson, R.M., Zettle, R.M. and Halperin, M.L. New clinical approach to evaluate disorders of potassium excretion. Miner. Electrolyte Metab. 12: 234-238, 1986.

68. Zettle, R.M., West, M.L., Josse, R.G., Richardson, R.M. and Marsden, P.A. Renal potassium handling during states of low aldosterone bioactivity: a method to differentiate renal and nonrenal causes. Am. J. Nephrol. 7: 360-365, 1987. 